\title{
Endotoxaemia in active Crohn's disease. Treatment with whole gut irrigation and 5-aminosalicylic acid
}

\author{
W WELLMANN, P C FINK, F BENNER, AND F W SCHMIDT \\ From the Department of Internal Medicine, Division of Gastroenterology and Hepatology, Medizinische \\ Hochschule Hannover, FRG
}

SUMMARY Endotoxins in plasma were monitored during treatment in 18 patients hospitalised for acute exacerbation of Crohn's disease: systemic endotoxaemia was found on admission in all but one. The patients were randomly divided into two groups: one receiving treatment with total parenteral nutrition and steroids. To decrease the absorbable endotoxin pool, the other group was additionally treated with whole gut irrigation and 5-aminosalicylic acid was added to the lavage fluid. In most of these patients endotoxaemia cleared after intestinal lavage and they needed shorter hospitalisation. Earlier improvement was also indicated by a faster decrease of the Crohn's disease activity index and vanHees index. In the group receiving conservative treatment alone, endotoxaemia was controlled within three weeks. We conclude that endotoxaemia occurs in most patients suffering from active Crohn's disease. Control of endotoxaemia after intestinal lavage suggests that systemic endotoxaemia is caused by absorption of endotoxins from the gut. Earlier improvement after whole gut irrigation indicates its beneficial effect in active Crohn's disease.

Disturbed permeability of the mucosa and subsequent absorption of macromolecules has been found in patients suffering from inflammatory bowel disease. ${ }^{12}$ Disorganisation of tight junctions shown by electron microscopy ${ }^{3}$ is probably a site of leakage from the gut, which may account for increased titres of antibodies against bacterial antigens in inflammatory bowel disease. ${ }^{4-6}$ Along with increased permeability of the mucosa, bacterial overgrowth of the gut was shown in inflammatory bowel disease. ${ }^{78}$ To date no microbial agent has been identified as the causative agent of Crohn's disease or ulcerative colitis. ${ }^{9}$ The combination of an abnormal microflora and a damaged mucosal barrier, however, may be relevant to chronic inflammatory bowel disease, through possible hazards of circulating bacterial antigens. Most studies have reported systemic endotoxaemia in active inflammatory bowel disease. ${ }^{10-13}$ The importance of these results is not known and to our knowledge no study has so far documented endotoxaemia during treatment. The significance of endotoxin determination is unclear, as systemic

Address for correspondence: P D Dr med W Wellmann, Div. Gastroenterology, Med. Hochschule. Konstanty-Gutschow-Str. 8, 3 Hannover 61. FR Germany.

Received for publication 11 October 1985 endotoxaemia was not recorded in all studies concerned with this problem. ${ }^{14} 15$

The coexistence of an abnormal microflora of the bowel and a damaged mucosal barrier was the reason for our previous studies of whole gut irrigation in the treatment of inflammatory bowel disease. The results obtained in a controlled pilot study $^{16}$ suggested a beneficial use of intestinal lavage in patients suffering from Crohn's disease. In patients with severe inflammatory bowel disease, endotoxaemia was controlled after whole gut irrigation. $^{17}$

The present investigation was designed to examine the incidence of endotoxaemia in active Crohn's disease and the significance of toxic compounds absorbed from the bowel by correlation with the course of relapses and by comparison of groups treated either with conventional therapy or in addition with intestinal lavage, a treatment modality which may be expected to be anti-endotoxinaemic.

\section{Methods}

PATIENTS

Patients hospitalised for exacerbation of known Crohn's disease entered the study if the Crohn's 
disease activity index ${ }^{18}$ was $>150$. Patients under 16 years of age and pregnant women were excluded. Patients with involvement of the upper gastrointestinal tract as the sole manifestation of Crohn's disease were not eligible. We also excluded patients who needed surgical treatment for high grade stenosis, abscess formation, or fistulae to the urinary tract. Patients with known bowel stenosis entered the study if there was no evidence of prestenotic dilation.

Patient's data are given in Table 1. The diagnosis of Crohn's disease was established in all patients by characteristic radiograph findings; pseudotuberculosis had been ruled out. In patients suffering from Crohn's colitis the diagnosis was also confirmed by endoscopy and histology. One patient in each group had undergone previous resection. Two patients in the control group and three in the lavage group had perianal fistulae. On admission one patient in each group had fever above $38 \cdot 5^{\circ} \mathrm{C}$. All patients allocated to the lavage group gave informed consent before treatment. Randomisation was in blocks of four patients.

\section{TREATMENT}

From the first day of hospital admission all patients were given total parenteral nutrition for at least one week and $2300 \mathrm{Kcal}$ per $24 \mathrm{~h}$ were given in a volume of $2500 \mathrm{ml}$ through a central venous catheter. To avoid interference with reticulo-endothelial system function, solutions containing fatty acids were not used. All patients received $0.75 \mathrm{mg} / \mathrm{kg}$ of prednisone orally. If the colon was diseased sulphasalazine $3 \mathrm{~g}$

Table 1 Patients' data

\begin{tabular}{|c|c|c|}
\hline & Control group & $\begin{array}{l}\text { Whole gut } \\
\text { irrigation }\end{array}$ \\
\hline \multicolumn{3}{|l|}{ Sex } \\
\hline Men & 4 & 4 \\
\hline Women & 5 & 5 \\
\hline Age (years) mean & $22 \cdot 4$ & $28 \cdot 7$ \\
\hline range & $18-48$ & $17-48$ \\
\hline \multicolumn{3}{|l|}{ Duration of discase } \\
\hline $\begin{array}{l}\text { (months) mean } \\
\text { range }\end{array}$ & $\begin{array}{l}48 \cdot 4 \\
20-120\end{array}$ & $\begin{array}{l}58 \cdot 2 \\
20-144\end{array}$ \\
\hline $\begin{array}{l}\text { Duration of present } \\
\text { relapse (weeks) mean } \\
\text { range }\end{array}$ & $\begin{array}{l}6 \cdot 6 \\
4-10\end{array}$ & $\begin{array}{l}5 \cdot 0 \\
2-8\end{array}$ \\
\hline \multicolumn{3}{|l|}{ Pretreatment } \\
\hline steroids & 2 & 2 \\
\hline sulphazalazin & 1 & 2 \\
\hline steroids + sulphazalazin & 6 & 5 \\
\hline \multicolumn{3}{|l|}{ Discase site } \\
\hline Ileitis & 2 & 2 \\
\hline Ilcocolitis & 5 & 5 \\
\hline Colitis & 2 & 2 \\
\hline
\end{tabular}

per day was given. Patients with perianal fistulae received metronidazole $800 \mathrm{mg}$ per day. Although we were aware that metronidazole might hinder the interpretation of results, the reported benefit of this therapy ${ }^{19}{ }^{20}$ forced us not to withhold it. If the Crohn's disease activity index decreased by at least $20 \%$ after one week, the central venous catheter was withdrawn and further nutrition consisted of a peptide diet. One thousand, eight hundred millilitres per day containing $2000 \mathrm{Kcal}(400 \mathrm{mosm} / \mathrm{l})$ were administered through an intraduodenal tube. At the same time the steroid dose was reduced to $0.5 \mathrm{mg} / \mathrm{kg}$ prednisone. If the initial Crohn's disease activity index value decreased by at least $40 \%$, oral nutrition was started. Patients were discharged when the Crohn's disease activity index was below 120 and oral nutrition was tolerated.

\section{Technique of whole gut irrigation}

A size $12 \mathrm{FG}$ radioopaque polyvinyl tube was placed in the jejunum about $20 \mathrm{~cm}$ beyond the ligament of Treitz by means of a guide wire. ${ }^{21}$ An irrigator tube was placed in the rectum and was connected to a bag for collection of the lavage fluid, which was saline $0.9 \%$ warmed to $37^{\circ} \mathrm{C}$. A high flow-rate $9 \mathrm{l} / \mathrm{h}$ was used to achieve efficient washing and to minimise intestinal absorption. For early detection of high grade stenosis the flow of the lavage fluid was followed by sonography in patients with known stenosis. All patients in the lavage group had two lavages during the first week of hospitalisation on the days indicated in Table 2. In the first lavage 181 saline were administered, a volume that was effective and tolerable in our previous studies; two days later the lavage was repeated with $9 \mathrm{l}$. At the end of both lavages 5-ASA $4 \mathrm{~g}$ from a fresh suspension were added to the final $1.5 \mathrm{I}$ and the flow-rate was slowed to $3 \mathrm{l} / \mathrm{h}$.

In the first five patients who underwent intestinal lavage, serum sodium, potassium, and bicarbonate were determined before, during and by the following morning after whole gut irrigation. Body weight was determined in all patients every day.

\section{Determination of endotoxin}

Blood for endotoxin determination was drawn between 8 and 10 am from a forearm vein into a $2 \mathrm{ml}$ syringe which contained $0 \cdot 1 \mathrm{ml}$ of heparin. Care was taken to avoid air bubbles in the syringe and a new ampoule of heparin was used every day. The specimens were centrifuged and stored in pyrogen free glass tubes at $-60^{\circ} \mathrm{C}$. The laboratory was not aware to which treatment group the patients were allocated. Endotoxins in plasma were determined by a femtogram sensitive spectrophotometric assay, which has been described in detail. ${ }^{22}{ }^{23}$ The assay 
Table 2 Endotoxins in plasma $(\mu g / l)$

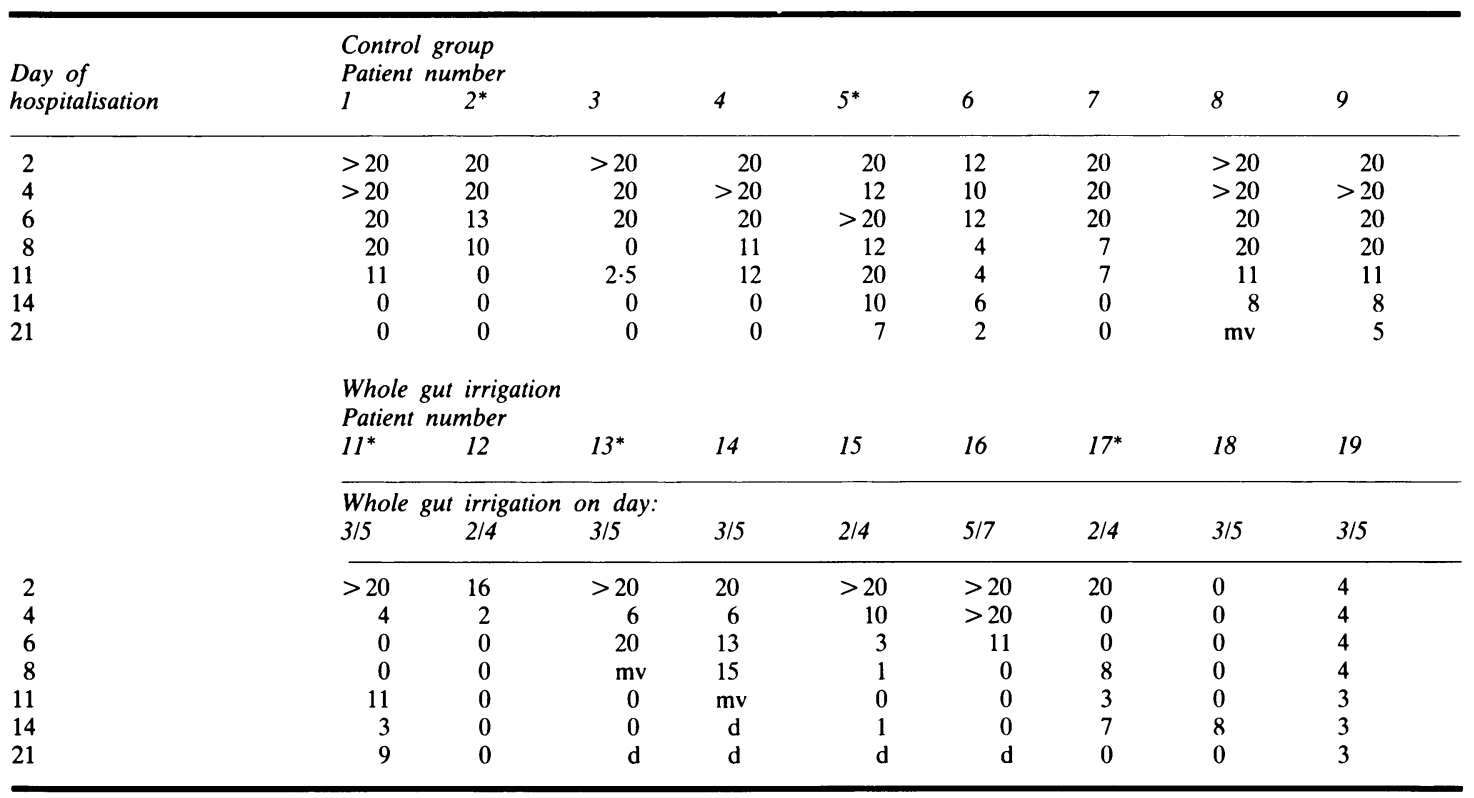

*=perianal fistula.

$\mathrm{mv}=$ missing value.

$\mathrm{d}=$ patient discharged.

allows determination between 0 and $20 \mu \mathrm{g} / \mathrm{l}$. The coefficient of variation is $8 \%$ in the lower range and $15 \%$ in the higher range. For statistical analysis values above $20 \mu \mathrm{g} / \mathrm{l}$ were computed as $20 \mu \mathrm{g} / \mathrm{l}$.

To assess the validity of the assay, endotoxin in plasma was determined in a previous study in 97 outpatients suffering from Crohn's disease. ${ }^{24}$ In this series 13 patients were positive for circulating endotoxin. The correlation between endotoxaemia and vanHees-index which encompasses serum albumin as the most important variable was $r=0.53$ ( $\mathrm{p}<0.0001$ Student's $t$ test).

\section{BACTERIOLOGICAL INVESTIGATIONS}

To rule out sources of endotoxaemia other than inflammatory bowel disease, bacteriological investigation of the urine was done once a week. Serological analysis included complement fixation tests for Yersiniosis and Salmonellosis. When the venous catheter was withdrawn the tip was forwarded for bacteriological analysis.

\section{ASSESSMENT OF THE THERAPEUTIC EFFECT}

Besides endotoxins in plasma the therapeutic effect was also assessed by the Crohn's disease activity index and the index compiled by vanHees et al. ${ }^{25}$ which also encompasses serum albumin and ESR.
Weekly routine laboratory examinations included serum iron.

\section{STATISTICAL ANALYSIS}

On the basis of the results obtained in a previous pilot study ${ }^{16}$ significant differences were expected after nine patients had been entered in each group. The results given represent the mean \pm SEM. Significance was tested using the Wilcoxon's two sample rank test. All tests were two tailed. Differences between the study groups were regarded as significant if $\mathrm{p}<0.05$.

\section{Results}

The period needed for this study was six months. During this time all patients hospitalised for exacerbation of Crohn's disease who fulfilled the entry criteria entered the study. Four patients had one of the exclusion criteria and were not randomised. Three of them underwent resection for high grade stenosis and one needed drainage of a perianal abscess. Whole gut irrigation was tolerated well by all the patients; one only asked for temporary reduction of the flow rate because of mild abdominal discomfort. The results of serum electrolyte determination showed no differences between the 
pre- and postlavage values. Body weight measured the following morning was not different from the prelavage values. All the serological tests were negative for Yersiniosis and Salmonellosis. No urinary tract, or catheter tip infection was found in any patient.

The time required for hospital treatment was $38.1 \pm 3.85$ days in the control and $23.7 \pm 3.0$ in the lavage group $(\mathrm{p}=0 \cdot 012)$.

Endotoxin in plasma was detected on admission in all patients in the control and in eight of nine patients in the lavage group (Table 2). There were no significant differences between the two groups. Endotoxin in plasma declined gradually in the control group and was cleared within two weeks in five patients. A more rapid decline was found in the lavage group and significant differences between the groups were detected by days 4 to 11 (Fig. 1). The one patient in the lavage group in whom endotoxin in plasma was not detected on admission, needed the longest hospitalisation in this group. In four of five patients suffering from perianal fistulae endotoxin increased after an initial decrease (patients nos $5,11,13,17)$. In patient no 14 endotoxin in plasma declined after whole gut irrigation and although improvement was noted, endotoxin increased thereafter.

In both study groups all patients improved during treatment. The Crohn's disease activity index (Fig. 2) decreased more rapidly in the lavage group and was significantly lower than in the control group from the second week until discharge. The vanHees index (Fig. 3) was significantly different between the groups at week 3 only. Serum iron (Fig. 4) increased significantly at week 1 in the lavage group and remained raised until week 3 . In the two patients

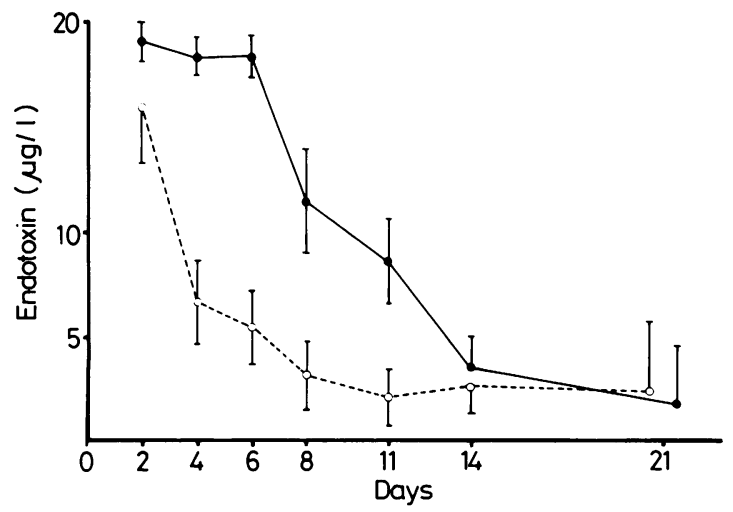

Fig. 1 Plasma endotoxin concentrations in controls and after whole gut irrigation - - - Mean $\pm S E M$, $n=9$. Significance $p=0.60$ (day 2), 0.002 (4), 0.003 (6), $0.02(8), 0.02(11), 0.96(14), 0.83(21)$.

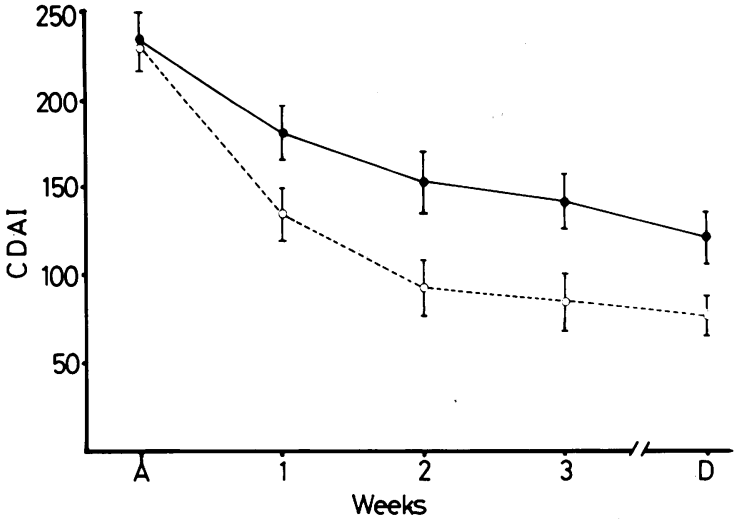

Fig. 2 CDAI on admission (A), weekly, and at discharge (D) in controls - and after whole gut irrigation - - - . Mean $\pm S E M, n=9$. Significance $p=0 \cdot 82(A), 0 \cdot 22(1)$, $0.03(2), 0.03(2), 0.03(D)$.

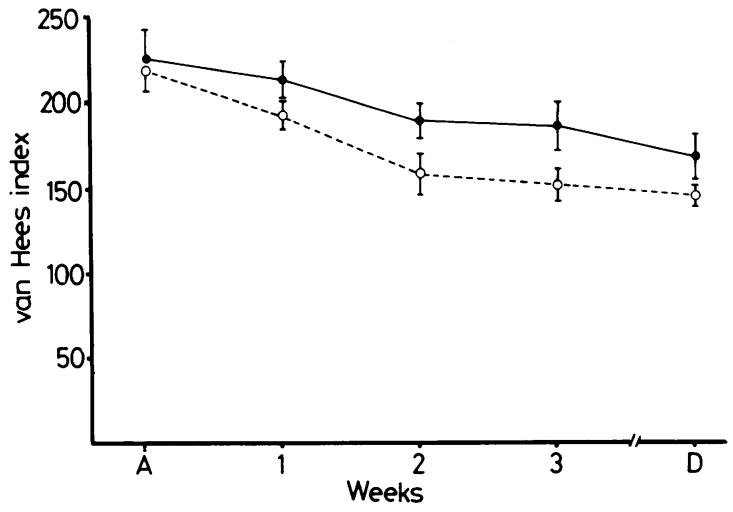

Fig. 3 vanHees-index on admission $(A)$, weekly, and at discharge $(D)$ in controls _- and after whole gut irrigation --- . Mean $\pm S E M, n=9$. Significance $p=0.57(A)$, $0.17(1), 0.08(2), 0.03(3), 0.27(D)$.

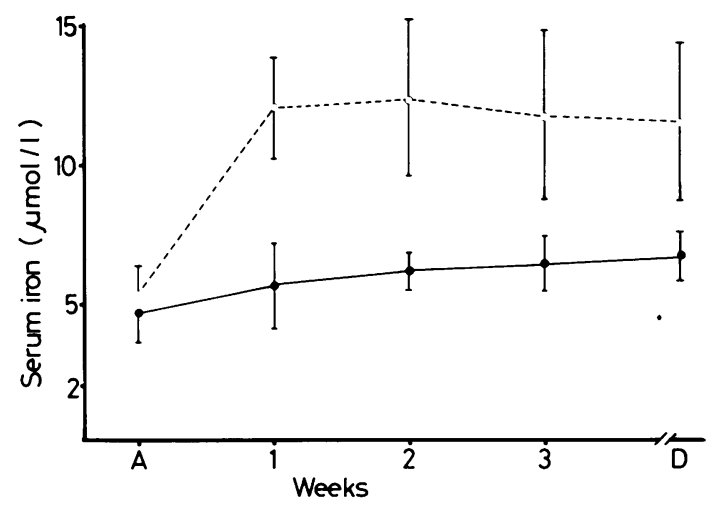

Fig. 4 Serum iron on admission $(A)$, weekly, and at discharge $(D)$ in controls - and after whole gut irrigation - - - Mean $\pm S E M, n=9$. Significance $p=0.69(A)$, $0.03(1), 0.01(2), 0.07(3), 0.05(D)$. 
who were pyrexial on admission, body temperature was normal by the third day. Fistula secretion decreased in all patients and ceased altogether in one patient (patient no 13).

All patients were seen in outpatients eight weeks and six months after discharge. Further improvement was noted and the Crohn's disease activity index was below 120 in all.

\section{Discussion}

There were no significant differences between the study groups on admission. The population studied may be regarded as representative but the number of patients with previous resections was lower than expected.

This study shows that whole gut irrigation was well tolerated by virtually all nine patients. Although large quantities of saline were given, electrolyte disturbance or weight gain were not detected. Besides the high flowrate which limits the time for absorption of saline, we attribute this good tolerance probably to impaired capacity of saline absorption in Crohn's disease. ${ }^{26} 27$

Endotoxin in plasma was detected in 17 of 18 patients on admission. This is in keeping with previous studies, which showed the association of endotoxaemia and active disease. On conservative treatment endotoxaemia was cleared within three weeks in most patients, but decreased faster in the lavage group. After whole gut irrigation decreased endotoxaemia was found in all endotoxinaemic patients. The assumption that intestinal lavage caused the decrease of plasma endotoxin is supported by the close coincidence of decreased endotoxins with the day the intestinal lavage was performed, which strongly suggests that endotoxin in plasma originates from the bowel. The portal vein has been reported to be the most important route for endotoxin absorbed from the gut. Small amounts of endotoxin reaching the liver are regarded as physiological. ${ }^{28} 29$ Large amounts of endotoxin absorbed due to impaired mucosal barrier function may exhaust the capacity of the liver to clear the portal venous blood of endotoxin and may result in a spillover into the peripheral venous blood. ${ }^{30}$ The results obtained with most patients in the present study support this hypothesis. In two patients in the lavage group endotoxin in plasma did not correlate with disease activity. Despite a severe relapse, one patient was negative for circulating endotoxin. In another, endotoxin increased after an initial fall, despite marked clinical improvement. Endotoxin in plasma may be raised without relation to inflammatory bowel disease for three reasons: the specimen may be contaminated despite careful sampling, or the test may be positive because of lack of specificity. ${ }^{31}$ A further explanation for raised endotoxin in plasma may be stress. ${ }^{32} \mathrm{~A}$ negative test for endotoxin in plasma may be caused by an inhibitor, or may show true absence of circulating endotoxin. As the patient negative for endotoxin experienced a severe relapse, we conclude that systemic endotoxaemia is occasionally not found in active Crohn's disease.

As correlation between the presence of perianal fistulae and endotoxaemia was found, two more sources of endotoxaemia have to be taken into consideration. Endotoxins circumventing the liver may originate from the fistula, or may be released and absorbed due to treatment with metronidazole. Increased liberation of endotoxin may be caused by metronidazole and has been reported for other antibiotics. ${ }^{33}$

It may be argued that decrease of plasma endotoxin is not related to whole gut irrigation, but a consequence of possible anti-endotoxinaemic properties of 5-ASA. 5-ASA was given because remarkable benefit was reported from local therapy with this drug in patients suffering from ulcerative colitis. ${ }^{34} 35$ Intestinal lavage offers the opportunity to use this in patients with inflammatory bowel disease in the small bowel, or right colon. The antiinflammatory properties of 5-ASA are likely to result from local effects on prostaglandin metabolism $^{36}$ and may thus act to stabilise the mucosal barrier. The results of our pilot study, which was done without the use of 5-ASA suggest, that improvement is also achieved with intestinal lavage alone. To clearly separate the effects of whole gut irrigation from the effects of 5-ASA a third group of patients receiving whole gut irrigation without 5-ASA will be needed. As there is little doubt about the beneficial use of 5-ASA in inflammatory bowel disease we do not believe that such a study is worthwhile.

The intestinal lavage group improved within $60 \%$ of the time required for the control group. There was early decrease of the Crohn's disease activity index and rapid increase of serum iron. The vanHees index decreased after three weeks. Was better outcome related to decreased endotoxin? The biological effects of endotoxins have most often been studied in laboratory animals. Reference to possible effects in man is difficult, because the effects of acute, or chronic endotoxaemia have been studied. From the natural history of Crohn's disease intermittent endotoxaemia is expected, which may result in a state of tolerance, not studied until now. Studies in man showed that endotoxin may cause fever, ${ }^{37}$ particularly in patients treated with immunosuppressive drugs. ${ }^{38}$ The two pyrexial patients 
in the present study were afebrile soon after hospitalisation, although endotoxaemia continued. Thus endotoxaemia is not necessarily associated with pyrexia. Endotoxin may cause a rapid and profound decrease of serum iron. ${ }^{39}$ Lactoferrin released from leukocytes is probably a mediator of endotoxins which causes hyposiderinaemia. ${ }^{40}$ These considerations allow the hypothesis, that endotoxins play a role in the hyposiderinaemia. The increase of serum iron would thus reflect a decreased release of lactoferrin. Determinations of serum lactoferrin could test this hypothesis.

The present investigation could not be done in a blind manner, so that patient's and observer's bias cannot be excluded. As an important result the hospital stay was significantly lower in the lavage group. Discharge was defined by a decrease of the Crohn's disease activity index below 120 . In several studies the Crohn's disease activity index has proven a reliable parameter for the severity of Crohn's disease and subjective interpretation is unlikely. Among the measurements of therapeutic effect the vanHees index which is considered to reflect inflammatory activity is independent of subjective interpretation. The better outcome of the lavage group therefore allows the suggestion that benefit may be due to the lavage. Apart from decreased bacterial antigens, further possible modes of therapeutic effect may be a decreased penetration of bacteria which has been demonstrated in a study on pathogenic bacteria in mesenteric lymph nodes and ileal serosa during Crohn's disease surgery. ${ }^{41}$ An additional effect of whole gut irrigation may be removal of small bowel effluent which has recently been shown to cause inflammatory reactions in the colon of patients treated by split ileostomy. ${ }^{42}$

We gratefully acknowledge the skilful advice received from Dr H Hecker, Dept. of Biomathematic. We wish to thank Dr J Scheffler, Henning Company, Berlin, for a generous supply of 5-ASA.

\section{References}

1 Walker, WA, Isselbacher KJ. Uptake and transport of macromolecules by the intestine. Possible role in clinical disorders. Gastroenterology 1974; 67: 531-50.

2 Sundquist T, Magnusson KE, Sjödahl R, Stjernström I, Tagesson C. Passage of molecules through the wall of the gastrointestinal tract. Gut 1980; 21: 208-14.

3 Martin ML, Greenstein AJ, Geller SA, Gordon RE, Aufses AH. A freeze fracture study of Crohn's disease of the terminal ileum: Changes in epithelial tight junction organisation. Am J Gastroenterol 1983; 9: 537-47.

4 Auer IO, Röder A, Wensinck F, van de Merve JP,
Schmidt H. Selected bacterial antibodies in Crohn's disease and ulcerative colitis. Scand J Gastroenterol 1983; 18: 463-70.

5 Matthews N, Mayberry JF, Rhodes J, et al. Agglutinins to bacteria in Crohn's disease. Gut 1980; 21: 376-80.

6 Blaser MJ, Miller RA, Lacher J, Singleton JW. Patients with active Crohn's disease have elevated serum antibodies of seven enteric pathogens. Gastroenterology 1984; 87: 888-94.

7 Beeken WL, Kamich RE. Microbial flora of the upper small bowel in Crohn's disease. Gastroenterology 1973; 65: $390-7$.

8 Rutgeerts P, Ghoose Y, Vantrappen G, Eyssen H. Ileal dysfunction and bacterial overgrowth in patients with Crohn's disease. Eur J Clin Invest 1981; 11: 199-206.

9 Kirsner JB, Shorter RG. Recent developments in nonspecific inflammatory bowel disease. $N$ Engl $J$ Med 1982; 306: 837-46.

10 Colin R, Grancher T, Lemeland JF, et al. Endotoxemia in patients with inflammatory enterocolitis. Gastroenterol Clin Biol 1979; 3: 15-9.

11 Juhlin L, Krause U, Shelley WB. Endotoxin-induced microlots in ulcerative colitis and Crohn's disease. Scand J Gastroenterol 1980; 15: 311-4.

12 Aoki KA. A study of endotoxemia in ulcerative colitis and Crohn's disease. Acta Med Okayama 1978; 32: 147-58.

13 Liehr H. Endotoxins and the pathogenesis of hepatic and gastrointestinal diseases. In: Frick P, von Harnack GA, Kochsiek K, Martini GA, Prader A, eds. Advances in internal medicine and pediatrics. Berlin: Springer Verlag, 1982: 118-93.

14 Palmer KR, Duerden BI, Holdsworth CD. Bacteriological and endotoxin studies in cases of ulcerative colitis submitted to surgery. Gut 1980; 21: 851-4.

15 Kruis W, Schussler P, Weinzierl M, Galanos C, Eisenburg J. Circulating lipid A antibodies despite absence of systemic endotoxemia in patients with Crohn's disease. Dig Dis Sci 1984; 29: 502-7.

16 Wellmann W, Schmidt FW. Intestinal lavage in the treatment of Crohn's disease: a pilot study. Klin Wochenschr 1982; 60: 371-3.

17 Wellmann W, Fink PC, Schmidt FW. Whole gut irrigation as antiendotoxinaemic therapy in inflammatory bowel disease. Hepato-Gastroenterol 1984; 31: 91-3.

18 Best WR, Becktel JM, Singleton JW, Kern F. Development of a Crohn's disease activity index. Gastroenterology 1976; 70: 439-44.

19 Bernstein LH, Franks MS, Brandt LJ, Boley SJ. Healing of perineal Crohn's disease with metronidazole. Gastroenterology 1980; 79: 357-65.

20 Brandt LJ, Bernstein LH, Boley SJ, Frank MS. Metronidazole therapy for perianal Crohn's disease: A follow-up study. Gastroenterology 1982; 83: 383-7.

21 Nolan DJ. Rapid duodenal and jejunal intubation. Clin Radiol 1979; 30: 183-5.

22 Fink PC, Lehr L, Urbaschek RM, Kozak J. Limulus amebocyte lysate test for endotoxaemia. Klin Wochenschr 1981; 59: 213-8.

23 Fink PC, Grunert JH. Endotoxaemia in intensive care 
patients: A longitudinal study with the limulus amebocyte lysate test. Klin Wochenschr 1984; 62: 986-91.

24 Wellmann W, Fink PC, Benner F. Endotoxinämie bei entzündlichen Darmerkrankungen. Verh Ges Inn Med 1984; 90: 827-9.

25 vanHees PAM, vanElteren $\mathrm{PH}$, vanLier $\mathrm{HJJ}$, vanTongeren JHM. An index of inflammatory activity in patients with Crohn's disease. Gut 1980; 21: 279-86.

26 Hawker PC, McKay JS, Turnberg LA. Electrolyte transport across the colonic mucosa from patients with inflammatory bowel disease. Gastroenterology 1980 ; 79: 508-11.

27 Allan RN, Steinberg DM, Dixon K, Cooke WT. Changes in the bidirectional sodium flux across the intestinal mucosa in Crohn's disease. Gut 1975; 16: 201-4.

28 Nolan JP, Camara DS. Endotoxin, sinusoidal cells, and liver injury. In: Popper H, Schaffner F, eds. Progress in liver disease. New York: Grune and Stratton, 1982: 361-76.

29 Jakob AJ, Goldberg PHK, Bloom N, Degenshein GA, Kozinn PHJ. Endotoxin and bacteria in portal blood. Gastroenterology 1977; 72: 1268-70.

30 Bradfield JWB. Control of spillover. The importance of Kupffer cell function in clinical medicine. Lancet 1974; 2: 883-6.

31 Stumacher KJ, Kovnatt MJ, McCabe WR. Limitations of the usefulness of the limulus assay for endotoxin. $N$ Engl J Med 1973; 288: 1261-4.

32 Walker RI. Endotoxin and stress. Lancet 1974; 2: 527-8.
33 Anderson BM, Solberg O. The endotoxin-liberating effect of antibiotics in vitro. Acta Pathol Microbiol Immunol Scand 1980; 88: 231-6.

34 Willoughby CP, Piris L, Truelove SC. The effect of topical $\mathrm{N}$-acetyl-5-amino-salicylic acid in ulcerative colitis. Scand J Gastroenterol 1980; 15: 715-9.

35 Campieri M, Lanfranchi GA, Bazzocchi G, et al. Treatment of ulcerative colitis with high-dose 5-aminosalicylic acid. Lancet 1981; 2: 270-1.

36 Sharon P, Stenson WF. Enhanced synthesis of Leukotriene $\mathrm{B}_{4}$ by colonic mucosa in inflammatory bowel disease. Gastroenterology 1984; 86: 453-60.

37 Dinarello CA, Wolff SM. Molecular basis of fever in humans. Am J Med 1982; 72: 799-819.

38 Harris RI, Stone PCW, Evans GR, Stuart J. Endotoxaemia as a cause of fever in immunosuppressed patients. J Clin Pathol 1984; 37: 467-70.

39 Kampschmidt RF, Upchurch HF. Effects of bacterial endotoxin on plasma iron. Proc Soc Exp Biol Med 1962; 184: 191-6.

40 Van Snick JL, Masson PL, Heremans JF. The involvement of lactoferrin in the hyposiderinemia of acute inflammation. J Exp Med 1974; 140: 1068-84.

41 Ambrose NS, Johnson M, Burdon DW, Keighley MRB. Incidence of pathogenic bacteria from mesenteric lymph nodes and ileal serosa during Crohn's disease surgery. Br J Surg 1984; 71: 623-5.

42 Harper PH, Lee ECG, Kettlewell MGW, Bennett MK, Jewell DP. Role of the faecal stream in the maintenance of Crohn's colitis. Gut 1985; 26: 279-84. 